\title{
School pressures and child mental health in Afro-Asian countries
}

\author{
L. B. Bartlet
}

Educational pressure on children is worldwide. In the United Kingdom this is seen in the growth of structured classes and courses for two- to fouryear-olds such as 'Making French Fun' and 'Musical Appreciation for Under Fours' (Matthews, 1995). Such programmes are of particular interest to aspiring middle-class parents but other groups also have high educational expectations. Some parents with a West Indian background, believing the British educational system to be superior to that in their country of origin. look for high attainments which often results in their children showing psychosomatic symptoms. In developing countries the signs of educational pressure are especially evident.

The apocryphal tales from the 1950 s and ' $60 \mathrm{~s}$ of job applicants in India describing themselves as 'B. A. Bombay (failed)' are not without significance. Formal education was and still is seen in most Afro-Asian countries as the key to a better life free from poverty and hardship. In courses for postgraduate doctors, requests for 'certificates' on the last day of the course were not uncommon. This underlines the importance attached to paper qualifications at all levels. Where examinations are concerned, tensions can run high. In the 80 s there were several reports of students in Pakistan taking revolvers into examination halls to ward off invigilators. In both India and Pakdstan there have been protest meetings when students have judged the marking of their papers to be unfair or biased.

Of young children T. S. Eliot wrote "The heavy burden of the growing soul perplexes and offends more day by day". Nowhere is this more true than in Asia and Africa. The principal of a prestiglous college in Uttar Pradesh informed me that each year the evening before enrolment day parents of four-year-olds queue and camp out in the college grounds to ensure that their children's names get on the list. Such schools often have entrance examinations for the little ones. A Lucknow colleague described how a four-year-old failed the examination at a Muslim school. When asked where God is, he pointed upwards. His fate was sealed as the answer he should have given was 'everywhere'. In the children's column of an English language newspaper in Lahore in 1988 a mother wrote bewailing the weight of books her four-year-old had to carry each day. She surveyed her son's class and found that the burden borne by these children every day averaged six kilos.

It is noticeable that the strain on the very young impinges most strongly where the families are wealthy and make use of private schools a long way from the family home. In Bangkok, for example, many children in the upper social classes as young as six-years-old spend 4-5 hours a day in the back of cars going and coming from school. Leaving home before $7.00 \mathrm{am}$, they often do not return before 7 or $8.00 \mathrm{pm}$.

Health professionals in these countries are beginning to understand the links between stress and bodily function. There was agreement at a general practitioners' forum in Lucknow a few years ago that school examinations always produced a wave of psychosomatic problems. Sadly, the subsequent discussion indicated that once organic illness had been ruled out and tranquillisers prescribed, general practitioners rarely took time to explain the 'illness'. So parents gained no further understanding of the nature of the problem. In the same city the head of an expenstve private school gave a telling example of the importance attached to school attendance. He noticed in assembly a sickly, clearly jaundiced 12-year-old. He sent the lad home, recommending immediate medical attention and no further school attendance until better. Four days later he spotted the boy in the school corridor still jaundiced. When questioned the boy confirmed he still felt ill but was back in school as his parents were worried about forthcoming examinations. The incident was interesting in a secondary way - the problem had been missed or ignored by the school staff in closest contact with the pupil concerned.

Japanese children have punishing, highly competitive school routines. Pressures increase as children reach their teens. Many adolescents attend private 'crammer' institutions in the evening, after the standard school day has finished. Parental expectations are commonly 
high. There is little leisure time and alternative, non-scholastic outlets for creative physical and affective expression are limited in comparison with the West. Emotional expression is curtailed in other ways. Social conformity is valued highly, restricting antisocial, negative manifestations of feeling. Hierarchical considerations inhibit emotions relating to teachers and the school system. Somatisation offers one form of escape. This may be associated with school refusal (Yamazakd et al, 1992), an issue of great concern to Japanese authorities. Bullying (Ijime) is a major problem and is often a factor in school refusal. Bullying may be a particular risk in societies where hierarchy and conformity are important but it is also possible that students, failing in the education rat-race, give vent to their frustrations in this form of antisocial behaviour.

In China, educational resources are much more thinly spread, yet the stresses impinging on school children and students are similar. The scarcity of higher educational places means that pressures on children to gain entry to colleges and universities run dangerously high. Some young people are driven to write anonymously to the advice columns of youth magazines as their parents are totally deaf to their complaints. Poor studying conditions (inadequate lighting, semiillegible texts) add to children's problems which include eye strain (Hooper, 1985). A high proportion of students taking university examinations are not awarded places and see themselves as failures, suffering from loss of self-esteem.

Similar reports emanate from Africa. In Zambian schools the ethos is highly competitive and only about $50 \%$ of pupils finishing the first three years of senior school are permitted to complete the last two years. The failures are apparently stigmatised as drop-outs and emerge into a world of work ill prepared and frustrated (Chintu \& Haworth, 1979).

One of the first psychiatric reports from a developing country drawing attention to educational pressure was Prince's description of the Brain Fag Syndrome (Prince, 1960), where intensive study, lack of sleep, anxiety about important, future-determining examinations lead to a florid and sometimes transiently psychotic disturbance.

Most of the observations above relate to children of average and above average ability. As more children in the developing world are brought into the school system, teachers will be confronted with cases of learning disability, for which they are often inadequately trained and unable to recognise or help. This may lead to children suffering from unreasonable educational expectations.

It appears that the longer children stay in fulltime education the greater the strain, and it is at the senior stage that some resort to suicidal behaviour. This matter is of great concern to mental health workers in Japan (McClure \& Shiratakd, 1989).

Parents appear to be the primary source of pressure but the part played by school systems is also considerable. Parents relate educational achievement to a better way of life, especially in poor countries without social welfare support, but many have no understanding of the nature of intelligence and child development in general. Ramanujam (1968) describes a 10-year-old brought to his clinic for 'lack of interest in studies and obstinacy'. The child was listless and inattentive in school. Of normal intelligence, he was deprived of food three or four times a week because of poor reports from the teacher. He took to absenting himself from school to go to his grandparents' house nearby to get food - thereby worsening his school performance. The rapid reduction in family size is likely to have affected parental attitudes concentrating the hopes and aspirations of the older generations in a smaller pool of children. Only children experience early overindulgence followed by high expectation later.

Pressures from school staff are determined by a number of factors such as the reputation of the school, the need to satisfy parental demands and a limited grasp of child psychology and emotional development. In the West teachers often recognise excessive pressure at work and will tactfully encourage parents to go easy. Likewise parents will sense undue pressure falling on their children in school and move in protectively. Sadly, in AfroAsian countries parents and teachers often react quite differently, supporting and potentiating each other in pressurising children.

What can be done to ameliorate this widespread problem? First and foremost a better understanding of the basic principles of child mental health on the part of parents and professionals is needed. Paediatricians require not only to recognise somatisation but also how to talk about psychosomatic and functional disorders to parents, children and other workers, including teachers. Primary health doctors and their teams need to know about child development from the mental and psychological angle. The World Health Organization is aware of this and some promising programmes are in operation such as those pioneered by Nikapota in Sri Lanka (Nikapota, 1983). Above all, school teachers must acquire a better understanding of child mental health. Some years ago two mental health specialists in India ran and subsequently evaluated a course for school counsellors (Kapur \& Cariapa, 1979). Such initiatives need to be followed up. There may be resistance from school principals where teachers have large classes and giving time to individual children is hard to consider. 
It is heartening to discern in Asia the beginnings of serious research in the child mental health field. Child psychiatric services are still embryonic. Yet it should be possible to draw attention to school pressures through existing health and educational organisations. Forces will continue to pull in the opposite direction. Understandably, parental concern for good educational progress is here to stay.

\section{References}

CHINTU, C. \& HAWORTH, A. (1979) Mental health services for children in Zambia. Unpublished paper.

HOOPER, B. (1985) Youth in China. Harmondsworth: Penguin. KAPUR, M. \& CARIAPA, I. (1979) Evaluating a training programme for school teachers in student counselling. Indian Joumal of Psychiatry. 20. 289-291.

MCCluRe, M. \& SHIRATAK, S. (1989) Child Psychiatry in Japan. Journal of the American Academy of Child and Adolescent Psychiatry. 28, 488-492.
MATTHEWS, V. (1995) "Busy Bables". Independent on Sunday. June 18th.

NIKAPOTA. A. D. (1983) Development of Child Mental Health Services in Sri Lanka. Joumal of Tropical Paediatrics, 29. 302-305.

PRINCE, R. (1960) The "brain fag" syndrome in Nigerlan students. Joumal of Mental Sclence, 108, 559-570.

RAMANUAM, B. K. (1968) Behaviour disorders of school going children. Archives of Child Health, 10, 48-60.

YAMAZAK, K., INOMATA, J., MAKTA, K., et al (1960) Japanese culture and neurotic manifestations in childhood. In Yearbook of the International Association for Child and Adolescent Psychiatry and Allied Professionals leds C. Chiland \& G. Young). pp. 384-391. New Haven: Yale Untversity Press.

L. B. Bartlet, Hon. Consultant Psychiatrist, Paediatric Medical Unit, Southampton General Hospital, Tremona Road, Southampton SO16 6YD

\section{Caring for a Community}

\section{The Community Care Policy of the Royal College of Psychiatrists}

\section{by Dinesh Bhugra, Keith Bridges and Chris Thompson}

This report presents some examples of philosophy, approaches, good practices, and service aspirations found in the UK. Some of these services have resulted from Government policy and research into specific psychiatric disorders while others have drawn upon developments abroad. Many services, however, have developed based on clinical experiences, pragmatism, a sensitivity to local needs, collaborative approaches involving a variety of local organisations, and the desire of practitioners to have available to the public an effective range of services. The report describes actual and potential community services providing for the mental health needs of the severely mentally ill.

\section{$\bullet £ 10.00 \bullet 90 p p . \bullet 1995 \bullet$ ISBN $090224177 \mathrm{X}$}

Available from bookshops and from the Publications Department, Royal College of Psychiatrists, 17 Belgrave Square, London SW1X 8PG (Tel. 0171-235 2351 extension 146) 